\title{
Motivasi Belajar Bahasa Jepang Mahasiswa Program Studi Pendidikan Bahasa Jepang Universitas Muhammadiyah Yogyakarta
}

\author{
DEDI SURYADI*1, ROSI ROSIAH ${ }^{2}$ \\ 'Program Studi Pendidikan Bahasa Jepang Universitas Muhammadiyah \\ Yogyakarta \\ Jl. Brawijaya, Tamantirto, Kasihan, Bantul, Daerah Istimewa Yogyakarta 55183 \\ e-mail:dedisuryadi@umy.ac.id, rosi.rosiah@umy.ac.id
}

\begin{abstract}
ABSTRAK
Prestasi belajar bahasa Jepang dipengaruhi oleh faktor internal dan eksternal. Beberapa faktor di antaranya adalah motivasi belajar. Motivasi yang rendah dapat menimbulkan rasa malas dalam mengikuti perkuliahan. Untuk dapat mengetahui pengaruh metode pembelajaran dengan motivasi belajar maka diperlukan penelitian agar diperoleh jawaban yang akurat. Penelitian ini adalah penelitian pendahuluan yang akan berfokus pada bagaimana motivasi belajar bahasa Jepang mahasiswa Program Studi Pendidikan Bahasa Jepang UMY. Populasi penelitian ini adalah mahasiswa Program Studi Pendidikan Bahasa Jepang UMY yang berjumlah 104 orang yang tersebar dalam tujuh kelas. Pengambilan sampel yang berjumlah 60 mahasiswa dilakukan dengan teknik proportional random sampling. Variabel yang dikaji dalam penelitian ini yaitu motivasi belajar. Sumber data berasal dari data primer dan sekunder. Hasil penelitiannnya adalah mahasiswa Program Studi Pendidikan Bahasa Jepang sebagian besar mempunyai pengalaman belajar bahasa Jepang dengan belajar mandiri atau otodidak. Motivasi terbesar belajar bahasa Jepang adalah agar dapat berkomunikasi dengan bahasa Jepang. Sedangkan kendala dalam proses belajar bahasa Jepang adalah sulitnya belajar huruf Jepang seperti hiragana, katakana dan kanji.

Kata kunci : minat. motivasi ,belajar ,bahasa Jepang.
\end{abstract}

\begin{abstract}
ABSTRACK
The learning achievement of Japanese is influenced by internal and external factors. Some of the factors are learning motivation. Low motivation can cause laziness in following the lecture. To be able to know motivation in learning Japanese the research is necessary to obtain an accurate answer. This research is a preliminary study that will focus on How to Motivate Japanese Language Study of Japanese Language Study Program of UMY. The population of this study is the Japanese Language Education Student of UMY which amounts to 104 people spread in 7 classes. The sampling of 60 students is done by proportional random sampling technique. the variables studied in this study is learning
\end{abstract}


motivation. The data source comes from primary and secondary data. The result of this research is Japanese Language Study Program Students Mostly have experience learning Japanese with self study or self-taught. The biggest motivation to learn Japanese is to communicate with Japanese. While the obstacles in the process of learning Japanese is hard to learn Japanese letters such as Hiragana, Katakana and Kanji.

Key Words : Motivation, Learning, Japanese Language

\section{PENDAHULUAN}

Adanya perbedaan prestasi belajar mahasiswa banyak dipengaruhi oleh berbagai faktor. Prestasi belajar dipengaruhi oleh dua faktor yaitu faktor internal dan faktor eksternal. Faktor internal yaitu faktor yang bersumber dari dalam individu seperti kecerdasan, perhatian, minat, bakat, motivasi, kematangan dan kesiapan. Sedangkan faktor eksternal adalah semua faktor yang bersumber dari luar seperti lingkungan. Lingkungan ini terdiri dari tiga yaitu lingkungan keluarga, lingkungan kampus, dan lingkungan masyarakat. Lingkungan keluarga meliputi cara orang tua mendidik, relasi antar anggota keluarga, suasana rumah, keadaan ekonomi keluarga, pengertian orang tua dan latar belakang kebudayaan. Lingkungan kampus meliputi metode mengajar, kurikulum, relasi dosen dengan Mahasiswa, relasi Mahasiswa dengan Mahasiswa, alat pelajaran, waktu perkuliahan dan lain-lain. Sedangkan lingkungan masyarakat meliputi keadaan Mahasiswa dalam masyarakat, mass media, teman bergaul dan bentuk kehidupan masyarakat. Berkaitan dengan proses interaksi belajar mengajar ada beberapa faktor yang perlu diperhatikan antara lain adalah motivasi belajar dan metode pembelajaran. Motivasi belajar merupakan salah satu faktor internal yang cukup penting dalam proses belajar mengajar. Motivasi diperlukan untuk menumbuhkan minat terhadap pelajaran yang diajarkan oleh dosen. Sedangkan metode pembelajaran juga salah satu faktor yang menentukan berhasil tidaknya proses belajar mengajar, dengan metode yang tepat secara otomatis akan mendukung pencapaian tujuan pembelajaran. Sehingga kedua faktor yang mempengaruhi prestasi belajar tersebut mempunyai andil yang cukup besar dalam kegiatan belajar. Belajar adalah salah satu kegiatan yang 
membutuhkan motivasi. Sayangnya motivasi ini tidak selalu timbul, sehingga terlihat ada Mahasiswa yang bersemangat, ada juga yang malas. Hal ini tercermin dari proses pembelajaran Bahasa Jepang di Program Studi Pendidikan Bahasa Jepang UMY.

Masih banyak mahasiswa terlihat belum termotivasi untuk mengikuti pelajaran bahasa Jepang yang disampaikan oleh dosen.

Dosen yang bersangkutan sudah berusaha membangkitkan motivasi mahasiswa untuk mengikuti kegiatan belajar namun hasilnya belum maksimal. Dosen banyak memberikan waktu

ekstra untuk mengembangkan tugas yang diberikan dan memperluas materi belajar. Selain itu dosen juga menilai setiap tugas dan memberikan komentar secara tertulis. Metode yang digunakan dosen dalam mengajar juga menentukan sikap

Mahasiswa, sehingga Mahasiswa kurang bersemangat dalam mengikuti kegiatan perkuliahan. Menggerakkan motivasi belajar dapat mendorong pencapaian prestasi belajar secara optimal. Walaupun Mahasiswa mempunyai bakat dan minat yang tinggi tetapi bila tidak disertai dengan motivasi belajar maka prestasi belajar tidak optimal begitu juga sebaliknya. Bisa juga Mahasiswa yang mempunyai intelegensi tinggi boleh jadi gagal karena kekurangan motivasi. Sehingga motivasi mempunyai peranan penting dalam kegiatan belajar karena motivasi adalah tenaga yang menggerakkan dan mengarahkan seseorang. Selain mamahasiswa unsur yang penting dalam kegiatan pembelajaran adalah dosen Di tangan dosenlah terletak kemungkinan berhasil atau tidaknya penyampaian tujuan belajar.

Pemilihan dan penggunaan metode yang tepat sesuai dengan tujuan kompetensi sangat diperlukan. Karena metode adalah cara yang digunakan oleh dosen untuk mengadakan hubungan dengan mahasiswa pada saat kegiatan belajar mengajar berlangsung. Untuk itu dosen sebagai pengarah dan pembimbing tidak hanya pandai dalam memilih metode pembelajaran namun usaha dosen-dosen untuk mengoptimalkan komponen pembelajaran diperlukan dalam rangka meningkatkan prestasi belajar. Bahasa Jepang merupakan sebuah mata kuliah yang 
membutuhkan kecermatan dan keseriusan sehingga metode yang digunakan harus sesuai agar mendapatkan hasil yang maksimal. Pengembangan metode yang tidak sesuai dengan tujuan pengajaran akan menjadi kendala untuk mencapai tujuan yang telah dirumuskan. Masalah yang timbul bagi mahasiswa adalah bagaimana cara belajar yang efektif yaitu sesuai dengan teknik belajar yang standar dengan berlatih melatih otaknya untuk belajar terus dengan keteraturan, bagaimana melakukan penyesuaian dengan dosen dan bagaimana menimbulkan kebiasaan teratur sehingga mencapai prestasi belajar yang optimal. Dari keterangan di atas peneliti mempunyai dugaan bahwa ada keterkaitan antara tinggi rendahnya motivasi belajar dengan metode pembelajaran yang digunakan.

\section{METODE PENELITIAN}

Dalam penelian ini, yang menjadi objek penelitian yaitu mahasiswa/i yang sedang kuliah di Program Studi Pendidikan Bahasa Jepang UMY. Dengan demikian jumlah responden dalam penelitan ini berjumlah 50 orang responden. Penentuan responden dalam penelitian ini akan menggunakan metode sampling kuota, yang mana penentuan sample respoden yang mempunyai ciri tertentu sampai jumlah yang diinginkan berdasarkan pada pertimbangan tertentu dari peneliti. Cara yang digunakan dalam sampling kuota yaitu dengan menetapkan jumlah responden yang di inginkan), maka jumlah tersebutlah dijadikan dasar untuk mengambil unit sampel yang diperlukan.

\section{TAHAPAN PELAKSANAAN DALAM PENELITIAN - Persiapan Penelitian}

Persiapan merupakan serangkaian aktifitas yang digunakan sebelum kegiatan penelitian dimulai. Dalam hal ini, peneliti akan melakukan persiapan yang berhubungan dengan penelitian, misalnya menyiapkan media dan instrumen dan menentukan respondent yang akan diteliti. 


\section{- Teknik Pengumpulan Data}

Setelah persiapan penelitian, peneliti akan mengumpulkan data dari respondent. Teknik yang digunakan yaitu dengan mengkombinasikan antara metode kualitatif dan metode kuantititif. Pada metode kualitatif, peneliti akan menggunakan survey dan metode wawancara pada metode kuantitatif. Di dalam survey, peneliti akan memberikan selembaran yang berisi sejumlah pertanyaan kepada responden. Sedangkan di wawancara, peneliti memberikan sejumlah pertanyaan secara oral kepada respondent. Hal ini dilakukan agar data yang diperoleh dari respondent dapat digali dan diperoleh secara luas dan mendalam.

\section{- Teknik Pengolahan dan Analisis Data}

Dalam pengolahan dan analisis data, peneliti akan mengelompokkan data yang diperoleh dari respondetn berdasarkan pada identifikasi permasalahan yang sesuai sehingga didapat hasil dan pemecahan dari Pengaruh media pembelajaran terhadap motivasi belajar bahasa Jepang di Prodi Pendidikan Bahasa Jepang UMY. Dalam hal ini, peneliti akan menerapkan teori Miles dan Huberman (1992) yang terdiri atas reduksi data, penyajian data, dan penarikan kesimpulan.

Reduksi data merupakan suatu proses pemilihan, penggolongan, dan penyederhanaan data- data yang diperoleh di lapangan kedalam bentuk yang sederhana. Dalam hal ini, peneliti akan mengumpulkan semua data dan mengelompokkan data tersebut kedalam bentuk yang sederhana. Penyajian data adalah suatu proses penyusunan data-data dari lapangan. Di dalam proses ini, terdapat dugaan-dugaan sementara akan permasalahan yang diteliti. Terakhir yaitu penarikan kesimpulan, yang mana bagian akhir dari penelitian. Di bagian penarikan kesimpulan tersebut akan menjawab rumusan permasalahan yang diteliti oleh peneliti.

Pendekatan yang digunakan dalam peneltian ini adalah Kualitatif dengan metodelogi penelitian survey terhadap 
Mahasiswa Prodi Pendidikan Bahasa Jepang sebanyak 104 mahasiswa dengan instrumen berupa angket sebanyak 6 soal mengenai motivasi belajar mahasiswa. Pengambilan data dilaksanakan pada hari Senin tanggal 15 Mei 2017. Setelah data diperoleh kemuadian jawaban dari angket dihitung dengan cara mempresentasekan jawaban dari responden dengan menggunakan rumus :

$P=\frac{f}{n} \times 100 \%$

(Nana, 2001:19)

Keterangan :

$\mathrm{P}:$ Persentase

$f$ : Jumlah Jawaban

$n$ : Jumlah Responden

\section{PEMBAHASAN}

Dari hasil Angket yang disebarkan ke 50 Mahasiswa Program Studi Pendidikan Bahasa Jepang, diperoleh data sebagai berikut;

Butir soal no 1 ; Sebelum masuk jurusan/program studi yang anda jalani sekarang apakah Anda pernah belajar bahasa Jepang sebelumnya?

Jawaban Mahasiswa :

TABEL 1

DISTRIBUSI JAWABAN ANGKET NOMOR 1

\begin{tabular}{llllll}
\hline ANGKATAN & 2013 & 2014 & 2015 & 2016 & RATA- RATA \\
\hline Pernah belajar bahasa Jepang & 63 & 53 & 74 & 56 & $61,5 \%$ \\
$\begin{array}{l}\text { Belum pernah belajar Bahasa } \\
\text { Jepang sebelumnya }\end{array}$ & 37 & 47 & 26 & 44 & $38,5 \%$ \\
\hline
\end{tabular}

Dari tabel di atas dapat ditarik kesimpulan bahwa mahasiswa Prodi Pendidikan Bahasa Jepang sebagian besar pernah belajar bahasa Jepang sebelum masuk ke Prodi PBJ. Sedangkan kurang dari setengahnya lagi belum pernah belajar bahasa Jepang. Perbandingan antara yang pernah dan yang belum seimbang.

Butir no 2 : Berapa lama Anda pernah belajar bahasa Jepang sebelumnya? 
Jawaban mahasiswa :

TABEL 2

DISTRIBUSI JAWABAN ANGKET NOMOR 2

\begin{tabular}{|c|c|c|c|c|c|c|}
\hline \multicolumn{2}{|c|}{ ANGKATAN } & 2013 & 2014 & 2015 & 2016 & RATA- RATA \\
\hline a. & Kurang dari 6 Bulan & 16 & 9 & 4 & 24 & $13,25 \%$ \\
\hline b. & Kurang dari setahun & 11 & 15 & 11 & 8 & $11,25 \%$ \\
\hline c. & Lebih dari 1 tahun & 32 & 32 & 52 & 24 & $35 \%$ \\
\hline d. & Kurang dari 2 tahun & 5 & 6 & 4 & 4 & $4,75 \%$ \\
\hline
\end{tabular}

Dari Tabel di atas dapat diketahui bahwa dari $35 \%$ mahasiswa PBJ UMY pernah belajar bahasa Jepang selama lebih dari satu tahun , 13,25\% pernah belajar kurang dari enam bulan dan 11, $25 \%$ pernah belajar Bahasa jepang kurang dari setahun, dan 4\% kurang dari enam bulan dan kurang dari 2 tahun.

Butir Soal angket no 3 : Dimana anda pernah belajar bahasa Jepang?

Jawaban angket

TABEL 3

DISTRIBUSI JAWABAN ANGKET NOMOR 3

\begin{tabular}{|c|c|c|c|c|c|}
\hline ANGKATAN & 2013 & 2014 & 2015 & 2016 & RATA- RATA \\
\hline SMA/SMK/MA & 11 & 38 & 48 & 32 & $32,25 \%$ \\
\hline b. Kursus Bahasa & 0 & 6 & 0 & 8 & $3,5 \%$ \\
\hline c. Privat & 5 & 0 & 7 & 4 & $4 \%$ \\
\hline d. Belajar Sendiri & 79 & 29 & 26 & 20 & $38,5 \%$ \\
\hline
\end{tabular}

TABEL 4

DISTRIBUSI JAWABAN ANGKET NOMOR 4

\begin{tabular}{llllll}
\hline ANGKATAN & 2013 & 2014 & 2015 & 2016 & RATA- RATA \\
\hline Jumlah Responden & 19 & 34 & 27 & 25 & 104 \\
a. Minat & 79 & 71 & 70 & 88 & $77 \%$ \\
b. Tidak berminat & 5 & 9 & 4 & 0 & $4,5 \%$ \\
c. Ragu ragu & 16 & 21 & 26 & 0 & $15.75 \%$ \\
\hline
\end{tabular}

Yang pernah belajar Bahasa Jepang sebelum masuk Prodi PBJ sebagian besar pernah belajar Sendiri dan belajar Bahasa Jepang di SMU/ SMK/ MA dengan presentase masing - masing 38\% dan $32,25 \%$. tapi ada sebagian kecil yang pernah belajar Bahasa jepang dari mengikuti Privat sebnyak 3,5 \% dan belajar di kursus Bahasa Jepang sebanyak 3,5\%. 
Butir soal angkat no 4 Apakah anda berminat belajar bahasa Jepang setelah lulus dari program studi yang anda tempuh sekarang?

Sebagian besar mahasiwa berminat belajar Bahasa Jepang setelah lulus dari prodi sekarang terus melanjutkan belajar sebanyak $77 \%$, sebagian kecil ada yang tidak berminat atau menjawab ragu ragu untuk melanjutkan belajar Bahasa Jepang setelah lulus dengan presetase $4,5 \%$ dan $15,75 \%$

Butir soal angket no 5 : Tujuan/Alasan Mempelajari Bahasa Jepang

Jawaban mahasiswa :

TABEL 5

DISTRIBUSI JAWABAN ANGKET NOMOR 5

\begin{tabular}{|l|l|l|l|l|l|}
\hline BUTIR PERTANYAAN & 2013 & $\begin{array}{l}2014 \\
19\end{array}$ & $\begin{array}{l}2015 \\
27\end{array}$ & $\begin{array}{l}2016 \\
25\end{array}$ & $\begin{array}{l}\text { RATA- } \\
\text { RATA } \\
104\end{array}$ \\
\hline $\begin{array}{l}\text { 1. Untuk mempelajari budaya } \\
\text { Jepang (Sejarah, Sastra) }\end{array}$ & $74 \%$ & $47 \%$ & $85 \%$ & $72 \%$ & $69,5 \%$ \\
\hline $\begin{array}{l}\text { 2. Untuk mempelajari Budaya } \\
\text { Jepang (anime, manga, J-Pop) }\end{array}$ & $65 \%$ & $26 \%$ & $59 \%$ & $68 \%$ & $55,5 \%$ \\
\hline $\begin{array}{l}\text { 3. Untuk mempelajari Politik, } \\
\text { Ekonomi dan Teknologi Jepang }\end{array}$ & $32 \%$ & $26 \%$ & $63 \%$ & $40 \%$ & $40,25 \%$ \\
\hline $\begin{array}{l}\text { 4. Karena Tertarik pada Bahasa } \\
\text { Jepang itu sendiri }\end{array}$ & $71 \%$ & $42 \%$ & $81 \%$ & $76 \%$ & $67,5 \%$ \\
\hline $\begin{array}{l}\text { 5. Agar dapat berkomunikasi } \\
\text { dalam bahasa Jepang }\end{array}$ & $91 \%$ & $63 \%$ & $96 \%$ & $80 \%$ & $82,5 \%$ \\
\hline $\begin{array}{l}\text { 6. Untuk mempersiapkan ujian } \\
\text { (ujian masuk perguruan tinggi, } \\
\text { pascasarjana, ujian kualifikasi } \\
\text { dsb }\end{array}$ & $53 \%$ & $37 \%$ & $52 \%$ & $48 \%$ & $47,5 \%$ \\
\hline $\begin{array}{l}\text { 7. Karena ingin melanjutkan } \\
\text { kuliah S2 di universitas di } \\
\text { Jepang }\end{array}$ & $63 \%$ & $53 \%$ & $67 \%$ & $76 \%$ & $64,75 \%$ \\
\hline $\begin{array}{l}\text { 8. Karena dalam pekerjaan yang } \\
\text { sekarang membutuhkan } \\
\text { kemampuan bahasa Jepang }\end{array}$ & $41 \%$ & $26 \%$ & $26 \%$ & $28 \%$ & $30,25 \%$ \\
\hline $\begin{array}{l}\text { 9. Karena disarankan oleh orang- } \\
\text { orang di sekeliling seperti } \\
\text { keluarga dan kerabat untuk } \\
\text { belajar bahasa Jepang }\end{array}$ & $29 \%$ & $5 \%$ & $22 \%$ & $32 \%$ & $22 \%$ \\
\hline $\begin{array}{l}\text { 10.Untuk mempersiapkan } \\
\text { kunjungan jangka pendek atau } \\
\text { menerima tamu orang Jepang } \\
\text { dalam rangka kegiatan } \\
\text { pertukaran dan persahabatan } \\
\text { dengan Jepang }\end{array}$ & $26 \%$ & $16 \%$ & $26 \%$ & $48 \%$ & $29 \%$ \\
\hline
\end{tabular}




\begin{tabular}{|c|l|l|l|l|l|}
\hline $\begin{array}{c}\text { 11.Karena akan berguna dalam } \\
\text { pekerjaan di masa depan } \\
\text { karena bercita cita ingin } \\
\text { bekerja di Jepang }\end{array}$ & $62 \%$ & $42 \%$ & $74 \%$ & $72 \%$ & $62,5 \%$ \\
\hline $\begin{array}{c}\text { 12.Untuk berdarmawisata atau } \\
\text { melakukan perjalanan wisata } \\
\text { ke Jepang }\end{array}$ & $68 \%$ & $47 \%$ & $81 \%$ & $64 \%$ & $65 \%$ \\
\hline $\begin{array}{c}\text { 13.Karena pada lembaga tempat } \\
\text { belajar atau bekarja sekarang } \\
\text { diharuskan mempelajari } \\
\text { bahasa Jepang }\end{array}$ & $32 \%$ & $21 \%$ & $11 \%$ & $32 \%$ & $24 \%$ \\
\hline $\begin{array}{c}\text { 14.Sebagai syarat untuk bisa } \\
\text { memahami pemahaman } \\
\text { internasional/lintas budaya } \\
\text { khususnya dengan Negara } \\
\text { Jepang }\end{array}$ & $50 \%$ & $11 \%$ & $59 \%$ & $60 \%$ & $45 \%$ \\
\hline $\begin{array}{c}\text { 15.Untuk mempersiapkan diri } \\
\text { apabila diterima bekarja di } \\
\text { perusahaan Jepang baik di } \\
\text { Indonesia maupun di Jepang }\end{array}$ & $76 \%$ & $37 \%$ & $74 \%$ & $60 \%$ & $61,75 \%$ \\
\hline $\begin{array}{c}\text { 16.Karena Ingin mendapatkan } \\
\text { sertifikat kelulusan Japanese } \\
\text { Profience Test (JLPT) }\end{array}$ & $79 \%$ & $47 \%$ & $85 \%$ & $76 \%$ & $71,5 \%$ \\
\hline $\begin{array}{l}\text { 17. Tujuan dan alasan lain di luar } \\
\text { pilihan 1-16 }\end{array}$ & $18 \%$ & $11 \%$ & $22 \%$ & $16 \%$ & $16,75 \%$ \\
\hline
\end{tabular}

Dari tabel di atas dapat ditarik kesimpulan bahwa tujuan belajar mahasiswa Bahasa Jepang adalah untuk ;

1. Agar dapat berkomunikasi dalam bahasa Jepang,

2. Karena Ingin mendapatkan sertifikat kelulusan Japanese Profience Test (JLPT)

3. Karena Tertarik dengan bahasas Jepang itu sendiri

4. Untuk mempelajari budaya Jepang (Sejarah, Sastra)

5. Karena akan berguna dalam pekerjaan di masa depan karena bercita cita ingin bekerja di Jepang,

6. Untuk berdarmawisata atau melakukan perjalanan wisata ke Jepang

7. Karena ingin melanjutkan kuliah S2 di universitas di Jepang

8. Untuk mempelajari Politik, Ekonomi dan Teknologi Jepang

9. Untuk mempelajari Budaya Jepang (anime, manga, J-Pop)

10.Untuk mempersiapkan diri apabila diterima bekarja di perusahaan Jepang baik di Indonesia maupun di Jepang

Butir soal no 6. Apa kira kira penyebab yang menghambat atau menghalangi anda untuk belajar bahasa Jepang? 
TABEL 6

DISTRIBUSI JAWABAN ANGKET NOMOR 6

\begin{tabular}{|c|c|c|c|c|c|}
\hline ANGKATAN & 2013 & 2014 & 2015 & 2016 & $\begin{array}{l}\text { RATA- } \\
\text { RATA }\end{array}$ \\
\hline $\begin{array}{l}\text { 1. Tidak ada lembaga atau } \\
\text { minimnya lembaga kursus } \\
\text { bahasa Jepang yang bagus } \\
\text { di sekitar anda }\end{array}$ & 11 & 38 & 19 & 36 & $26 \%$ \\
\hline $\begin{array}{l}\text { 2. Tidak ada nya guru atau } \\
\text { instruktur yang bisa } \\
\text { mengajar bahasa jepang di } \\
\text { sekitar anda }\end{array}$ & 0 & 35 & 22 & 48 & $26,25 \%$ \\
\hline $\begin{array}{l}\text { 3. Kurangnya informasi } \\
\text { mengenai lembaga kursus } \\
\text { bahasa Jepang di kota anda }\end{array}$ & 26 & 56 & 15 & 56 & $38,25 \%$ \\
\hline $\begin{array}{l}\text { 4. Susah nya belajar huruf } \\
\text { Jepang seperti Hiragana, } \\
\text { Katakana dan Kanji }\end{array}$ & 21 & 35 & 41 & 64 & $40,25 \%$ \\
\hline $\begin{array}{l}\text { 5. Kurangnya Fasilitas dan } \\
\text { kesempatan waktu untuk } \\
\text { belajar bahasa Jepang }\end{array}$ & 11 & 44 & 37 & 56 & $37 \%$ \\
\hline $\begin{array}{l}\text { 6. Tidak berminat untuk belajar } \\
\text { bahasa jepang lebih } \\
\text { mendalam karena tidak } \\
\text { menyukainya }\end{array}$ & 0 & 12 & 15 & 4 & $7,75 \%$ \\
\hline $\begin{array}{l}\text { 7. Tidak ada semangat dan } \\
\text { keinginan yang kuat untuk } \\
\text { bisa menguasai bahasa } \\
\text { Jepang baik lisan maupun } \\
\text { tulisan }\end{array}$ & 5 & 24 & 26 & 8 & $15,75 \%$ \\
\hline $\begin{array}{l}\text { 8. Kurangnya dana/biaya } \\
\text { pendukung untuk mengikuti } \\
\text { kursus atau pelatihan Bahasa } \\
\text { Jepang }\end{array}$ & 11 & 29 & 26 & 40 & $26,5 \%$ \\
\hline $\begin{array}{l}\text { 9. Kurangnya informasi } \\
\text { mengenai kegiatan } \\
\text { pendidikan, sekolah dan } \\
\text { Pekerjaan yang berhubungan } \\
\text { dengan Bahasa Jepang } \\
\text { khususnya dan Jepang pada } \\
\text { umumnya }\end{array}$ & 26 & 56 & 30 & 56 & $42 \%$ \\
\hline $\begin{array}{l}\text { 10. Tidak menyukai hal hal yang } \\
\text { berhubungan dengan } \\
\text { negara Jepang baik bahasa, } \\
\text { budaya atau yang lainnya. }\end{array}$ & 0 & 0 & 4 & 4 & $2 \%$ \\
\hline $\begin{array}{l}\text { 11. Kurang tersedianya buku } \\
\text { buku pembelajaran bahasa } \\
\text { Jepang di perpustakaan } \\
\text { kampus anda }\end{array}$ & 26 & 35 & 19 & 56 & $34 \%$ \\
\hline $\begin{array}{l}\text { 12. Kurangnya dukungan dari } \\
\text { orang tua untuk } \\
\text { mempelajari bahasa jepang }\end{array}$ & 11 & 15 & 7 & 12 & $11,25 \%$ \\
\hline $\begin{array}{l}\text { 13. Alasan lain diluar jawaban } \\
1-13\end{array}$ & 5 & 41 & 22 & 20 & $22 \%$ \\
\hline
\end{tabular}


Kendala yang dirasakan oleh Mahasiswa dalam mempelajar Bahasa Jepang disebabkan oleh hala hal tersebut di bawah ini ;

1. Kurangnya informasi mengenai kegiatan pendidikan, sekolah dan Pekerjaan yang berhubungan dengan Bahasa Jepang khususnya dan Jepang pada umumnya $42 \%$,

2. Susah nya belajar huruf Jepang seperti Hiragana, Katakana dan Kanji sebanyak 40,25\%,

3. Kurangnya informasi mengenai lembaga kursus bahasa Jepang di kota anda sebanyak 38,25\%,

4. Kurangnya Fasilitas dan kesempatan waktu untuk belajar bahasa Jepang sebanyak 37\%.

5. Kurang tersedianya buku buku pembelajaran bahasa Jepang di perpustakaan kampus anda sebanyak $34 \%$.

Menurut Lestari, Sri (2010) Faktor- faktor yang memperngaruhi motivasi pemilihan jurusan adalah faktor dalam diri, faktor motif sosial, dan faktor emosional. Yang termasuk ke dalam faktor dalam diri adalah ketertarikan, perhatian, tindakan, tujuan dan harapan. Faktor motif sosial adalah kebutuhan akan prestasi, kebutuhan untuk beraviliasi dengan orang lain, kebutuhan akan kekuasaan. Dan untuk faktor emosional adalah faktor yang berhubungan dengan sikap emosional yang tinggi.

Dari uraian di atas dapat dilihat, bahwa motivasi belajar Bahasa Jepang mahasiswa Program Studi Pendidikan Bahasa Jepang UMY kebanyakan dipengaruhi oleh faktor dalam diri dan faktor motif sosial.

\section{FAKTOR DALAM DIRI}

\section{a. Ketertarikan}

Berdasarkan hasil jawaban dari angket mengenai pengalaman belajar sebagian besar mahasiswa Program Studi Pendidikan Bahasa Jepang mempunyai pengalaman belajar sebelumnya, sehingga ketertarikan untuk belajar Bahasa Jepangpun tinggi.

\section{b. Tujuan}

Tujuan mahasiswa Program Studi Pendidikan Bahasa 
Jepang belajar Bahasa Jepang adalah untuk:

1) Agar dapat berkomunikasi dalam bahasa Jepang,

2) Karena Ingin mendapatkan sertifikat kelulusan Japanese Proficience Test (JLPT)

3) Karena Tertarik dengan bahasas Jepang itu sendiri

4) Untuk mempelajari budaya Jepang (Sejarah, Sastra)

5) Karena akan berguna dalam pekerjaan di masa depan karena bercita cita ingin bekerja di Jepang,

6) Untuk berdarmawisata atau melakukan perjalanan wisata ke Jepang

7) Karena ingin melanjutkan kuliah S2 di universitas di Jepang

8) Untuk mempelajari Politik, Ekonomi dan Teknologi Jepang

9) Untuk mempelajari Budaya Jepang (anime, manga, J-Pop)

10)Untuk mempersiapkan diri apabila diterima bekarja di perusahaan Jepang baik di Indonesia maupun di Jepang

\section{FAKTOR MOTIF SOSIAL}

Faktor Motif sosial yang muncul adalah kebutuhan akan prestasi, hal ini dapat dilihat dari jawaban angket mengenai tujuan belajar bahasa Jepang yang kebanyakan ingin bisa berkomunikasi dengan Bahasa Jepang, keingin mendapatkan sertifikat kelulusan Japanese Proficience Test (JLPT).

\section{KESIMPULAN}

Sebagian besar mahasiswa Prodi Pendidikan Bahasa Jepang pernah belajar bahasa Jepang sebelum masuk Perguruan Tinggi. Dengan lama belajar lebih dari satu tahun. Namun kurang dari dua tahun. Sebagian besar belajar dengan belajar sendiri dan menumpuh pendiidkan formal di SMA/ SMK/ MA. Setelah menyelesaikan Studi di Prodi Pendidikan Bahasa Jepang sebagian besar mahasiswa masih berminat untuk belajar bahasa Jepang.

Berdasarkan hasil angket dapat ditarik kesimpulan untuk motivasi belajar Mahasiswa prodi Pendidikan bahasa Jepang adalah, sebagai berikut: 
1. Agar dapat berkomunikasi dalam Bahasa Jepang

2. Karena Ingin mendapatkan sertifikat Kelulusan Japanese Proficience Test

3. Karena Tertarik dengan bahasa Jepamg itu sendiri

4. Untuk mempelajari Budaya Jepang (Sejarah, sastra)

5. Karena akan berguna dalam pekerjaan di masa depan karena bercita- cita ingin belajar di Jepang

6. Karena Ingin berdarmawisata atau melakukan perjalanan ke Jepang

7. Karena ingin melanjutkan kuliah S2 di universitas di Jepang

8. Untuk mempelajari Politik, ejkonomi, dan Teknologi Jepang

9. Untuk mempelajari Budaya Jepang (anime, manga, J-Pop)

10.Untuk mempersiapkan diri apabila diterima bekarja di perusahaan Jepang baik di Indonesia maupun di Jepang Sedangkan, untuk kendala dalam proses pembelajaran bahasa Jepang adalah sebagai berikut:

1. Susah nya belajar huruf Jepang seperti Hiragana, Katakana dan Kanji

2. Kurangnya Fasilitas dan kesempatan waktu untuk belajar bahasa Jepang

3. Kurangnya informasi mengenai kegiatan pendidikan, sekolah dan Pekerjaan yang berhubungan dengan Bahasa Jepang khususnya dan Jepang pada umumnya

4. Kurangnya dana/biaya pendukung untuk mengikuti kursus atau pelatihan Bahasa Jepang

5. Tidak ada nya guru atau instruktur yang bisa mengajar bahasa jepang di sekitar anda

6. Kurangnya informasi mengenai lembaga kursus bahasa Jepang di kota anda

Berdasarkan hasil temuan di atas. Diharapkan perguruan tinggi jurusan Pendidikan Bahasa Jepang dapat memfasilitasi tujuan mahasiswa untuk meningkatkan kemampuan berkomunikasi dengan menambah kesempatan mahasiswa untuk berkomunikasi dalam bahasa Jepang, misalnya melalui upaya optimalisasi perkuliahan Kaiwa, optimalisasi program himpunan mahasiswa 
dalam bidang peningkatan kemampuan komunikasi, program pelatihan JLPT, mengoptimalisasi program orientasi huruf Kana, dan meningkatkan metode pengajaran Kanji.

\section{DAFTAR PUSTAKA}

Anni, Chatarina Tri, dkk. 2006. Psikologi Belajar. Semarang: UPT MKK UNNES.

Arikunto, Suharsimi. 2002. Prosedur Penelitian Suatu Pendekatan Praktek. Jakarta: Rineka Cipta.

Darsono, Max. 2000. Belajar dan Pembelajaran. Semarang: CV. IKIP Semarang Press. . 2003.

Kamus Besar Bahasa Indonesia. Jakarta: Balai Pustaka.

Djamarah, Syaiful Bahri. 2002. Psikologi Belajar. Jakarta: Rineka Cipta.

Djamarah, Syaiful Bahri dkk. 2002. Strategi Belajar Mengajar. Jakarta: Rineka Cipta.

Lestari, Sri. 2010. Faktor- Faktor Yang Mempengaruhi Minat Siswa terhadap Pemilihan Program Studi Pendidikan Kewarganegaraan UNNES. Skripsi pada UNNES. Semarang : Tidak diterbitkan

Mappa, Syamsu. 1994. Teori Belajar Orang Dewasa. Jakarta: Departemen Pendidikan dan Kebudayaan.

Milles, M.B. and Huberman, M.A. 1984. Qualitative Data Analysis. London: Sage Publication

Nasution. 2003. Berbagai Pendekatan dalam Proses Belajar dan Mengajar. Jakarta: Bumi Aksara.

Rohani, Ahmad. 2004. Pengelolaan Pengajaran. Jakarta: PT. Rineka Cipta.

Sardiman, AM. 2006. Interaksi dan Motivasi Belajar Mengajar. Jakarta: PT. Raja Grafindo Persada. Syafri,

Sudjana, Nana dkk. 2001. Penelitian dan Penilaian Pendidikan. Bandung : Sinar Baru 